\title{
Anthracnose Disease of Carpetgrass (Axonopus compressus) Caused by Colletotrichum hainanense sp. nov.
}

\author{
Wu Zhang, ${ }^{1,2, \dagger}$ Ulrike Damm, ${ }^{3}$ Pedro W. Crous, ${ }^{4,5}$ Johannes Z. Groenewald, ${ }^{4}$ Xueli Niu, ${ }^{2}$ Jinmei Lin, ${ }^{2}$ and Yuting Li $^{2}$ \\ ${ }^{1}$ Institute for Advanced Materials, Lingnan Normal University, Zhanjiang 524048, China \\ ${ }^{2}$ School of Life Science and Technology, Lingnan Normal University, Zhanjiang 524048, China \\ ${ }^{3}$ Senckenberg Museum of Natural History Görlitz, 02806 Görlitz, Germany \\ ${ }^{4}$ Westerdijk Fungal Biodiversity Institute, 3584 CT Utrecht, The Netherlands \\ ${ }^{5}$ Department of Biochemistry, Genetics and Microbiology, Forestry and Agricultural Biotechnology Institute, University of Pre- \\ toria, Pretoria 0002, South Africa
}

\begin{abstract}
Carpetgrass (Axonopus compressus) is a creeping, stoloniferous, perennial warm-season grass that is adapted to humid tropical and subtropical climates. Recently, outbreaks of anthracnose disease of A. compressus caused by an unidentified Colletotrichum sp. were observed in the Hainan and Guangdong provinces in southern China. In late winter and early spring, the disease incidence reached $100 \%$ in some badly infected lawns. Under high-moisture conditions, the crowns and oldest leaf sheaths of the majority of the plants became necrotic, which led

Phylogenetic analyses of the combined internal transcribed spacer, Sod2, Apn2, and Apn2/Mat1 sequences revealed the pathogen to be a novel species of the Colletotrichum graminicola species complex. Microscopic examination showed that the species was also morphologically distinct from related Colletotrichum species. As a result of the phylogenetic, morphological, and pathogenicity analyses, we propose the name Colletotrichum hainanense for this pathogen of A. compressus in southern China.
\end{abstract} to whole lawns turning reddish brown. Pathogenicity was confirmed by inoculating uninfected $A$. compressus plants with a conidial suspension of the Colletotrichum sp. isolated from diseased Axonopus plants.
Keywords: multilocus phylogeny, new taxon, plant pathogen, systematics
Carpetgrass (Axonopus compressus [Sw.] P. Beauv.) is a creeping, stoloniferous, perennial, warm-season grass that is adapted to humid tropical and subtropical climates. Carpetgrass spreads quickly, and its flat, robust stolons form a dense, carpet-like turf on which its common name is based. Because carpetgrass grows quickly and is tolerant to heat, shade, and drought stress, it is popular in public lawns, used to promote water and soil conservation, and planted as slope protection to prevent erosion along highways throughout southern China (Guangdong, Guangxi, Yunnan, Fujian, Hainan, and Taiwan provinces) (Xi et al. 2006). A. compressus is largely free of diseases. To our knowledge, only two leaf diseases of carpetgrass have been reported in China, namely dollar spot caused by Sclerotinia homoeocarpa F.T. Benn. (Zhang et al. 2015a), and leaf spot caused by Curvularia lunata (Wakker) Boedijn (Zhang et al. 2017). In recent years, we have observed outbreaks of anthracnose on carpetgrass caused by a Colletotrichum species with curved conidia in southern China. Preliminary BLASTn searches with internal transcribed spacer (ITS) sequences indicated this species to belong to the Colletotrichum graminicola species complex.

Colletotrichum species cause diseases on a wide range of important crops, leading to significant economic losses (Afanador-Kafuri et al. 2014; Guarnaccia et al. 2017; Xu et al. 2018). Many species of Colletotrichum cause anthracnose diseases (Marin-Felix et al.

${ }^{\dagger}$ Corresponding author: W. Zhang; ldzw1987@163.com

Funding: This research was financially supported by the National Nature Science Foundation of China (grant no. 31602002), Science and Technology Innovation Strategy of Guangdong Province, China (2018A030313), and the Overseas Scholarship Program for Elite Young and Middle-aged Teachers of Lingnan Normal University.

The author(s) declare no conflict of interest.

Accepted for publication 8 January 2020.

(C) 2020 The American Phytopathological Society
2017). Systematic studies of the genus Colletotrichum revealed $\geq 14$ species complexes (Cannon et al. 2012; Damm et al. 2019; Marin-Felix et al. 2017). The Colletotrichum species associated with grasses form a monophyletic clade referred to as the graminicola clade, aggregate, or the $C$. graminicola species complex (Cannon et al. 2012). After an intensive molecular study and the description of six new species by Crouch et al. (2009c, d), Crouch and Beirn (2009) provided an overview of 14 Colletotrichum species that infect $>40$ plant genera in the Poaceae. Further studies included the epitypification of Colletotrichum falcatum and Colletotrichum sublineola and another new species, Colletotrichum eremochloae, all pathogens of Poaceae hosts (Crouch and Tomaso-Peterson 2012; Prihastuti et al. 2010). In contrast, Tao et al. (2013) isolated and described a number of endophytic Colletotrichum species from Bletilla ochracea (Orchidaceae) in China, of which two known and four new species belonged to the $C$. graminicola complex. Another four graminicolous Colletotrichum species closely related to Colletotrichum caudatum, all forming conidia with appendages, were introduced as the $C$. caudatum subaggregate belonging to the $C$. graminicola aggregate (Crouch 2014) and listed as a separate species complex by MarinFelix et al. (2017). The $C$. graminicola complex including the C. caudatum subaggregate currently comprises 22 accepted species (Marin-Felix et al. 2017).

It the past, Colletotrichum species have been differentiated based on morphological characters, such as size and shape of conidia, appressoria, acervuli, setae, or the identity of the host plant (von Arx et al. 1957; Sutton 1992). However, because of the variability of morphological characters within Colletotrichum species and overlapping ranges of conidial and colony characters between them, morphological identification is challenging. Therefore, molecular identification is today regarded as superior for species identification. The ITS region is the most widely used marker in fungal phylogenetic studies but has limitations, mainly because of its low resolution for distinguishing species, such as those of the genus Colletotrichum (Cai et al. 2009; Crouch et al. 2009b). For most Colletotrichum species additional loci are necessary for identification, and multilocus analyses are needed to characterize Colletotrichum species (Damm 
et al. 2012a, b, 2014, 2019; Guarnaccia et al. 2017; Weir et al. 2012). Crouch et al. (2009d) successfully used ITS, Sod2, Apn2, and Apn2/ Mat1 sequences for species delimitation within falcate-spored graminicolous Colletotrichum species, and Damm et al. (2009) differentiated the falcate-spored species from herbaceous hosts by using ITS, ACT, CHS-1, HIS3, GAPDH, and TUB2 sequences. Tao et al. (2013) used ITS, $A C T, G A P D H$, and TUB2, following the selection of loci by Damm et al. (2009).

The aim of this study was to identify and characterize the carpetgrass anthracnose pathogen in southern China by using morphological characteristics and multigene phylogenetic analysis and to confirm its pathogenicity.

\section{Materials and Methods}

Sample collection and fungal isolation. From January 2015 to July 2016, residences, colleges, and park lawns in the Hainan and Guangdong provinces in southern China were surveyed for anthracnose disease of carpetgrass. The leaves of carpetgrass with typical anthracnose symptoms were sampled and taken back to the laboratory. On 22 February 2016, the disease incidence (percentage of infected leaves) was assessed for five lawns in Haikou, Hainan Province. From each lawn, 100 leaves were selected randomly and inspected. The margin between diseased and healthy leaf tissues was cut into small pieces $(2 \times 4 \mathrm{~mm})$ to obtain fungal isolates. These pieces were surface-sterilized by sequential immersion in $75 \%$ ethanol for $30 \mathrm{~s}$ and $2 \% \mathrm{NaOCl}$ for $1 \mathrm{~min}$, then rinsed twice with sterile distilled water for $2 \mathrm{~min}$ and dried on sterilized paper towels. The pieces of disinfected carpetgrass samples were plated onto $2 \%$ potato dextrose agar (PDA, Crous et al. 2019) amended with $0.1 \%$ gentamicin sulfate. Isolates were incubated at $25^{\circ} \mathrm{C}$ under continuous light until fungal growth was observed. Hyphal tips (1 to $2 \mathrm{~mm}$ ) growing from leaf tissue were transferred onto PDA and maintained under $24 \mathrm{~h}$ fluorescent light at room temperature. After acervuli developed on the agar, single-spore cultures were prepared as explained by Zhang et al. (2015b). A total of 10 axenic cultures were transferred onto PDA slants and to 2-ml centrifuge tubes with $25 \%$ glycerol and stored at $4^{\circ} \mathrm{C}$ and, for long-term storage, at $-80^{\circ} \mathrm{C}$, respectively, in the Lingnan Normal University, Zhanjiang, Guang Dong, China. Because no morphological differences between the strains were observed, three strains were selected at random for further study (Table 1). The strains were also deposited in the culture collection of the Westerdijk Fungal Biodiversity Institute (CBS), Utrecht, the Netherlands. Specimens were deposited in the Museum of Beijing Forestry University, Beijing, China (BJFC).

Pathogenicity tests to fulfill Koch's postulates. The pathogenicity test was conducted with all three strains. Asymptomatic carpetgrass 'Huanan' sprigs were collected from fields in Zhanjiang city, planted in plastic pots $(12 \mathrm{~cm}$ in diameter, 10 sprigs/pot $)$ containing a sterile soil-peat-sand mixture $(\mathrm{wt} / \mathrm{wt} / \mathrm{wt}=2: 2: 1)$ and grown in a greenhouse at $25 \pm 2{ }^{\circ} \mathrm{C}$. The plants were fertilized once with $0.5 \mathrm{~g}$ 6-12-8 starter fertilizer (Haifeng, Anhui, China) per pot. From 1 month after sprigging, the plants were trimmed weekly for approximately 1 month, until the turfgrass canopy covered each pot.

To prepare inoculum, each fungal isolate was grown on PDA for 2 weeks under near-ultraviolet (UV) light. Conidia were removed from the surface of fungal colonies with distilled water, and the spore suspensions were adjusted to $1 \times 10^{5}$ conidia/ml. The potted carpetgrass plants were inoculated with $20 \mathrm{ml}$ of spore suspension sprayed on the foliage and crowns of each pot. Pots were covered with $30-\times$ $50-\mathrm{cm}$ polyethylene bags and incubated in a moist chamber at $25^{\circ} \mathrm{C}$. Control pots were sprayed with distilled water. The inoculation of the three strains and control were treated as four treatments. Pots were arranged in a completely randomized block design with five replicates per treatment. Two weeks after inoculation, the disease incidence (percentage of infected leaves) was assessed, and symptomatic leaf and sheath tissues were surface sterilized as described above and plated onto PDA to reisolate the fungi. The entire experiment was repeated once.

DNA extraction, PCR amplification, and sequencing. The DNA of the three strains was extracted with a DNA isolation kit according to the manufacturer's protocol. Four gene regions were analyzed as described by Crouch et al. (2006 and 2009c): the internal transcribed spacers and intervening $5.8 \mathrm{~S}$ nuclear ribosomal DNA (ITS), partial sequences of the manganese superoxide dismutase (Sod2), the $3^{\prime}$ end of the DNA lyase gene (Apn2) and the $5^{\prime}$ end of the DNA lyase gene, and mating type protein genes-like gene (Apn2/Mat1). The ITS region was amplified with the ITS1 and ITS4 primers (White et al. 1990), with the following PCR cycling parameters: $94^{\circ} \mathrm{C}$ for $4 \mathrm{~min} ; 35$ cycles of $94^{\circ} \mathrm{C}$ for $45 \mathrm{~s}, 60^{\circ} \mathrm{C}$ for $45 \mathrm{~s}$, and $72^{\circ} \mathrm{C}$ for $1 \mathrm{~min}$; and a final extension step at $72^{\circ} \mathrm{C}$ for $10 \mathrm{~min}$. The primer pair SOD625F/R was used to amplify a segment of the Sod2 gene (Crouch et al. 2006). Apn2 and Apn2/Mat1 were amplified with the primers Apn1W1F/R and Mat1M72F/R, respectively (Crouch et al. 2009c). PCR conditions and sequence reactions of Sod2, Apn2, and Apn2/Mat1 were performed as described by Crouch et al. (2006, 2009c). The PCR products were sent to Sangon Biotech Co., Ltd. (Shanghai, China) for DNA sequencing. Sequences were edited and assembled with DNAMAN version 5.2.2 and deposited in the GenBank nucleotide database of the NCBI (Table 1). The sequences were used in BLASTn searches on GenBank and for phylogenetic analyses.

Sequence data from type and reference strains of known Colletotrichum species of the $C$. graminicola species complex including its C. caudatum subaggregate (Cannon et al. 2012; Crouch 2014; Crouch et al. 2006, 2009a, c, d; Crouch and Tomaso-Peterson 2012; Moriwaki and Tsukiboshi 2009; Prihastuti et al. 2010; Tao et al. 2013) were obtained from NCBI GenBank. Although also belonging to the $C$. graminicola species complex, Colletotrichum cereale strains were used as outgroup in our analyses, because in other phylogenies this species is basal to all other species of this complex, even including the $C$. caudatum subaggregate (Cannon et al. 2012; Crouch 2014; Crouch et al. 2009c; Marin-Felix et al. 2017). Sequence alignments were performed with MAFFT version 7 (Katoh and Standley 2013) under the default settings. The alignments were manually adjusted in MEGA version 7 (Kumar et al. 2016). Phylogenetic analyses were conducted of each locus individually (data not shown) with maximum likelihood (ML), and the concatenated analyses of all four loci were based on Bayesian inference (BI), maximum parsimony (MP), and ML. For BI, the evolutionary model for each partition was determined with MrModeltest version 2 (Nylander 2004) and incorporated into the analysis. A Markov chain Monte Carlo algorithm was used to generate phylogenetic trees in MrBayes version 3.2.5 (Ronquist et al. 2012). The number of generations was set at 10 million, and the run was stopped automatically when the average standard deviation of split frequencies fell below 0.01. Trees were saved each 1,000 generations. The first $25 \%$ of the saved trees were discarded as "burn-in" phase, and posterior probability values were determined from the remaining trees. The MP analysis was carried out with Phylogenetic Analysis Using Parsimony, version 4.0 b10 (Swofford 2002). Phylogenetic relationships were estimated by heuristic searches with 1,000 random sequence additions. Tree bisection-reconnection was used, with the branch swapping option set on 'best trees only,' with all characters weighted equally and alignment gaps treated as missing data. The tree length (TL), consistency index (CI), retention index (RI), and rescaled consistence index (RC) were calculated for the MP phylogenies, and the bootstrap analysis (Hillis and Bull 1993) was based on 1,000 replications. The ML analyses, including 1,000 bootstrap replicates, were conducted with RAxML on the CIPRES portal (www.phylo.org) in RAxML-HPC BlackBox version 8.2.6. A general time reversible model (GTR) was applied with a gamma-distributed rate variation. The sequence alignment and the phylogenetic tree for the concatenated dataset were deposited in TreeBASE (http://purl.org/phylo/treebase/phylows/study/ TB2:S23635).

Morphological characterization. The species was characterized via techniques described previously (Cai et al. 2009). Mycelial plugs $(0.5 \mathrm{~mm}$ in diameter) were taken from the edges of 1-week-old colonies, transferred to the center of 9-cm-diameter PDA plates, and incubated at $25^{\circ} \mathrm{C}$ under 12 -h fluorescent light/12-h dark and near-UV light. The colony diameter of five replicate cultures of each isolate 
was measured daily for 1 week. The growth rate was calculated as the 7-day average of mean daily growth. Colony and microscopical characteristics were determined after 2 weeks of incubation. Formation of appressoria was induced via the glass culture technique (Cai et al. 2009; Johnston and Jones 1997) and observed after $24 \mathrm{~h}$. Morphological characters of hyphae, setae, conidia, and hyphal appressoria (e.g., shape and size) were evaluated from 50 structures with a dissecting microscope and a compound microscope with differential interference contrast illumination, both equipped with a high-definition color digital camera.

\section{Results}

Symptoms and isolation of the pathogen. In January 2015, anthracnose disease symptoms were first observed on carpetgrass grown under field conditions in public lawns of Haikou, Hainan Province. In summer 2015, the disease was also present in all lawns we inspected in the Guangdong Province. In February 2016, 89 to $100 \%$ of the plants of five lawns in Haikou were infected.

Initially, pale brown, elongated lesions with reddish brown margins developed on infected leaves. The lesions tapered sharply at the ends; some lesions coalesced to form larger, often irregularshaped lesions. Under high-moisture conditions, crowns and older leaf sheaths of the majority of the plants were affected, resulting in whole lawns appearing reddish brown. No symptoms were observed on stolons and roots (Fig. $1 \mathrm{~A}$ to C). Later, numerous acervuli with abundant setae, often in long rows parallel to the veins, developed on the infected leaves (Fig. 1D). Microscopic observations revealed these acervuli to release comparatively large $(\geq 20 \mu \mathrm{m})$ falcate conidia with acute apices. No sexual structures were found on the diseased leaf or stem tissues. Initially, no setae or spores were produced in culture on PDA. Under near-UV light at $25^{\circ} \mathrm{C}$ on PDA and in moist growth chambers, the production of conidia and setae and of hyphal appressoria, respectively, was induced. Sizes and shapes of conidia and setae were consistent with those observed on the plants in the field. The cultural and morphological characters were similar to those of several Colletotrichum species in the $C$. graminicola complex that are associated with warm-season grasses.

Pathogenicity tests to fulfill Koch's postulates. One week after inoculation with a conidial suspension, the Colletotrichum isolates had produced leaf and stem lesions consistent with the symptoms observed in the field. Hyphal appressoria were detected on chlorotic plants with a dissecting microscope. Two weeks after inoculation, plants were severely affected, and leaf tissue was degraded by necrotic lesions. In each treatment with a conidial suspension, $>50 \%$ of the leaves showed anthracnose symptoms. Acervuli developed subepidermally and released conidia 2 to 3 weeks after inoculation.

Table 1. GenBank and culture collection accession numbers of isolates used in this study

\begin{tabular}{|c|c|c|c|c|c|c|c|}
\hline \multirow[b]{2}{*}{ Species } & \multirow[b]{2}{*}{ Isolate $^{\mathbf{a}}$} & \multirow[b]{2}{*}{ Host } & \multirow[b]{2}{*}{ Location } & \multicolumn{4}{|c|}{ GenBank numberb } \\
\hline & & & & ITS & Sod2 & Apn2 & Apn2/Mat1 \\
\hline Colletotrichum alcornii & IMI $176619^{c}$ & Imperata cylindrica & Australia & JX076858 & - & - & - \\
\hline Colletotrichum axonopodis & IMI $279189^{c}$ & Axonopus fissifolius & Australia & MN521699 & - & EU364993 & FJ377907 \\
\hline Colletotrichum baltimorense & BPI $892771^{\mathrm{c}}$ & Sorghastrum nutans & USA & JX076866 & JX076886 & JX076927 & JX076905 \\
\hline Colletotrichum caudasporum & CGMCC $3.15106^{c}$ & Bletilla ochracea & China & JX625162 & - & - & - \\
\hline Colletotrichum caudatum & CBS $131602^{c}$ & Sorghastrum nutans & USA & JX076860 & JX076878 & JX076932 & JX076893 \\
\hline Colletotrichum cereale & CBS 305.69 & Ammophila arenaria & Germany & EU554109 & EU554213 & EU365016 & FJ377930 \\
\hline C. cereale & CBS 129663 & Bromus inermis & USA & DQ126177 & DQ133277 & - & FJ377977 \\
\hline Colletotrichum duyunense & CGMCC $3.15105^{\mathrm{c}}$ & Bletilla ochracea & China & JX625160 & - & - & - \\
\hline Colletotrichum echinochloae & MAFF $511473^{c}$ & Echinochloa utilis & Japan & AB439811 & AB440153 & - & - \\
\hline Colletotrichum eleusines & MAFF $511155^{\mathrm{c}}$ & Eleusines indica & Japan & JX519218 & EU554234 & EU365038 & - \\
\hline Colletotrichum endophytum & CGMCC $3.15108^{c}$ & Bletilla ochracea & China & JX625177 & - & - & - \\
\hline Colletotrichum eremochloae & CBS $129661^{\mathrm{c}}$ & Eremochloae ophiuroides & USA & JQ478447 & JQ478449 & - & JQ478462 \\
\hline C. eremochloae & CBS 129664 & Eremochloae ophiuroides & USA & JQ478446 & JQ478448 & - & - \\
\hline Colletotrichum falcatum & MAFF 306299 & Saccharum officinarum & Thailand & EU554112 & EU554215 & EU365019 & FJ377933 \\
\hline C. falcatum & MAFF 306170 & Saccharum officinarum & Japan & EU554111 & EU554214 & EU365018 & FJ377932 \\
\hline C. falcatum & CBS $127945^{c}$ & Saccharum officinarum & Indonesia & HM171677 & - & HM569770 & HM569769 \\
\hline Colletotrichum graminicola & CBS $130836^{c}$ & Zea mays & USA & DQ003110 & - & EU365081 & FJ377994 \\
\hline C. graminicola & CBS 130839 & Zea mays & Brazil & DQ003111 & - & EU365082 & FJ377995 \\
\hline Colletotrichum hainanense & XJ 9-1 = CBS $145900^{c}$ & Axonopus compressus & China & KY242705 & KY242711 & KY242714 & KY242708 \\
\hline C. hainanense & YF $10-2=C B$ & Axonopus compressus & China & KY242706 & KY242712 & KY242715 & KY242709 \\
\hline C. hainanense & ZW 3-12= CBS & Axonopus compressus & China & KY242707 & KY242713 & KY242716 & KY242710 \\
\hline Colletotrichum hanaui & MAFF $305404^{c}$ & Digitaria ciliaris & Japan & EU554101 & EU554205 & EU365008 & FJ377922 \\
\hline C. hanaui & MAFF 511014 & Digitaria ciliaris & Japan & EU554124 & EU554227 & EU365031 & FJ377944 \\
\hline Colletotrichum jacksonii & MAFF 511152 & Echinochloa esculenta & Japan & EU554130 & EU554233 & EU365037 & FJ377950 \\
\hline C. jacksonii & MAFF $305460^{c}$ & Echinochloa esculenta & Japan & EU554108 & EU554212 & - & FJ377929 \\
\hline Colletotrichum miscanthi & MAFF $510857^{c}$ & Miscanthus sinensis & Japan & EU554121 & EU554224 & EU365028 & - \\
\hline Colletotrichum navitas & CBS $125086^{c}$ & Panicum virgatum & USA & GQ919067 & GQ919073 & - & GQ919071 \\
\hline Colletotrichum nicholsonii & MAFF 305428 & Paspalum dilatatum & Japan & EU554103 & EU554207 & EU365010 & FJ377924 \\
\hline C. nicholsonii & MAFF $511115^{\mathrm{c}}$ & Paspalum dilatatum & Japan & EU554126 & EU554229 & EU365033 & FJ377946 \\
\hline Colletotrichum ochracea & CGMCC $3.15104^{c}$ & Bletilla ochracea & China & JX625156 & - & - & - \\
\hline Colletotrichum paspali & MAFF 511000 & Paspalum notatum & Japan & EU554123 & EU554226 & EU365030 & FJ377943 \\
\hline C. paspali & MAFF $305403^{c}$ & Paspalum notatum & Japan & EU554100 & EU554204 & EU365007 & FJ377921 \\
\hline Colletotrichum somersetense & CBS & Sorghastrum nutans & USA & JX076862 & JX076880 & JX076918 & JX076895 \\
\hline Colletotrichum sublineola & CBS $131301^{\mathrm{c}}$ & Sorghum bicolor & Burkina Faso & JQ005771 & DQ132051 & EU365121 & FJ378029 \\
\hline Colletotrichum zoysiae & MAFF $238573^{c}$ & Zoysia tenuifolia & Japan & JX076871 & - & JX076922 & JX076899 \\
\hline
\end{tabular}


In contrast, no symptoms were produced on the plants of the negative control. The fungus was successfully reisolated only from the inoculated, symptomatic plants.

Phylogenetic analysis. Based on BLASTn searches on GenBank, the species was confirmed to belong to the $C$. graminicola complex, and therefore molecular analyses with all available species of the $C$. graminicola species complex were performed. The alignments of the four loci, ITS, Sod2, Apn2, and Apn2/Mat1, were analyzed individually and as a combined alignment. The latter consisted of 35 sequences from species of the $C$. graminicola species complex and its $C$. caudatum subaggregate, including the outgroup, C. cereale. A total of 3,350 characters (ITS, 1 to 464; Sod2, 465 to 1,035; Apn2, 1,036 to 1,839; and Apn2/Mat1, 1,840 to 3,350) were included in the phylogenetic analyses, of which 2,040 characters were conserved, 315 variable, and 995 parsimony informative. The following models of evolution were recommended by MrModeltest and used for the BI analyses: GTR $+\mathrm{I}+\mathrm{G}$ for ITS and Apn2/Mat1, HKY $+\mathrm{G}$ for Sod2, and GTR+G for Apn2. A total of 8,702 trees were generated by BI, from which 2,174 trees were discarded as the "burn-in" phase, and posterior probabilities were calculated from the remaining 6,528 trees. The MP analysis resulted in four equally most parsimonious trees $(\mathrm{TL}=2,364, \mathrm{CI}=0.687, \mathrm{RI}=0.807, \mathrm{RC}=0.554)$. The phylogenetic tree inferred from a ML analysis is presented in Figure 2. The three strains from Axonopus formed a monophyletic clade, fully supported by bootstrap and posterior probability values (100/100/1), indicating them to represent a species that is distinct from other Colletotrichum species. This species clusters with Colletotrichum paspali and Colletotrichum nicholsonii strains with high support values $(99 / 98 / 1)$, forming a sister clade to a clade represented by Colletotrichum navitas and C. graminicola (100/100/1), together constituting a well-supported main clade on a long branch (99/100/1).
Another strain isolated from Axonopus in Australia (Colletotrichum axonopodis) is part of a different well-supported main clade together with Colletotrichum jacksonii, Colletotrichum echinochloae, and Colletotrichum hanai (99/99/1). Both the BI consensus tree and MP trees confirmed the tree topology obtained with ML. The single-locus analyses of ITS, Sod2, Apn2, and Apn2/Mat1 sequences consistently showed the three strains from Axonopus in China to form a wellsupported clade that was distinct from all other species of the $C$. graminicola species complex (data not shown).

Taxonomy. Colletotrichum hainanense W. Zhang \& X. L. Niu, sp. nov. MycoBank MB822332 Figure 3.

Etymology. Name refers to the Hainan Province of China, where this fungus was first collected.

Colonies on PDA raised with irregular margins, aerial mycelium dense, white to pale gray in the center, mouse gray toward the margin, reverse blackish gray in the center and pale brown toward the margin. Colonies 4.5 to $5.6 \mathrm{~cm}$ in 1 week, growth rate 6.5 to $8.0 \mathrm{~mm} / \mathrm{d}$. Conidiomatal acervuli formed abundantly. Setae septate, dark brown, 72 to $288.5 \mu \mathrm{m}($ mean $=154 \pm 68.0)$ long, base cylindrical to conical, 2 to $4 \mu \mathrm{m}(2.9 \pm 0.5 \mu \mathrm{m})$ diameter, apices acute. Conidiophores hyaline to pale brown, septate, sometimes branched. Conidia aseptate, fusiform, straight to curved, with acute to rounded ends, smooth-walled, hyaline, 19.5 to $27.5 \times 4$ to $7 \mu \mathrm{m}$ (mean $=23.6$ $\pm 2.0 \times 6.1 \pm 0.8 \mu \mathrm{m})$, length/width $(\mathrm{L} / \mathrm{W})$ ratio $=3.9$. Hyphae septate, branched, hyaline to pale brown, 1 to $6.5 \mu \mathrm{m}$ diameter, often guttulate. Hyphopodial appressoria pale to medium brown, smooth-walled, globose, ovoid, obovoid, or lobate, 10 to $16 \times 8.5$ to $11.5 \mu \mathrm{m}($ mean $=12.3 \pm 1.4 \times 10.1 \pm 0.9 \mu \mathrm{m}), \mathrm{L} / \mathrm{W}$ ratio $=1.2$.

Type. China, Hainan Province, Haikou City, from anthracnose on leaf of A. compressus, 18 December 2015, W. Zhang, holotype BJFC 010 (dried culture), culture ex-type XJ 9-1 = CBS 145900.
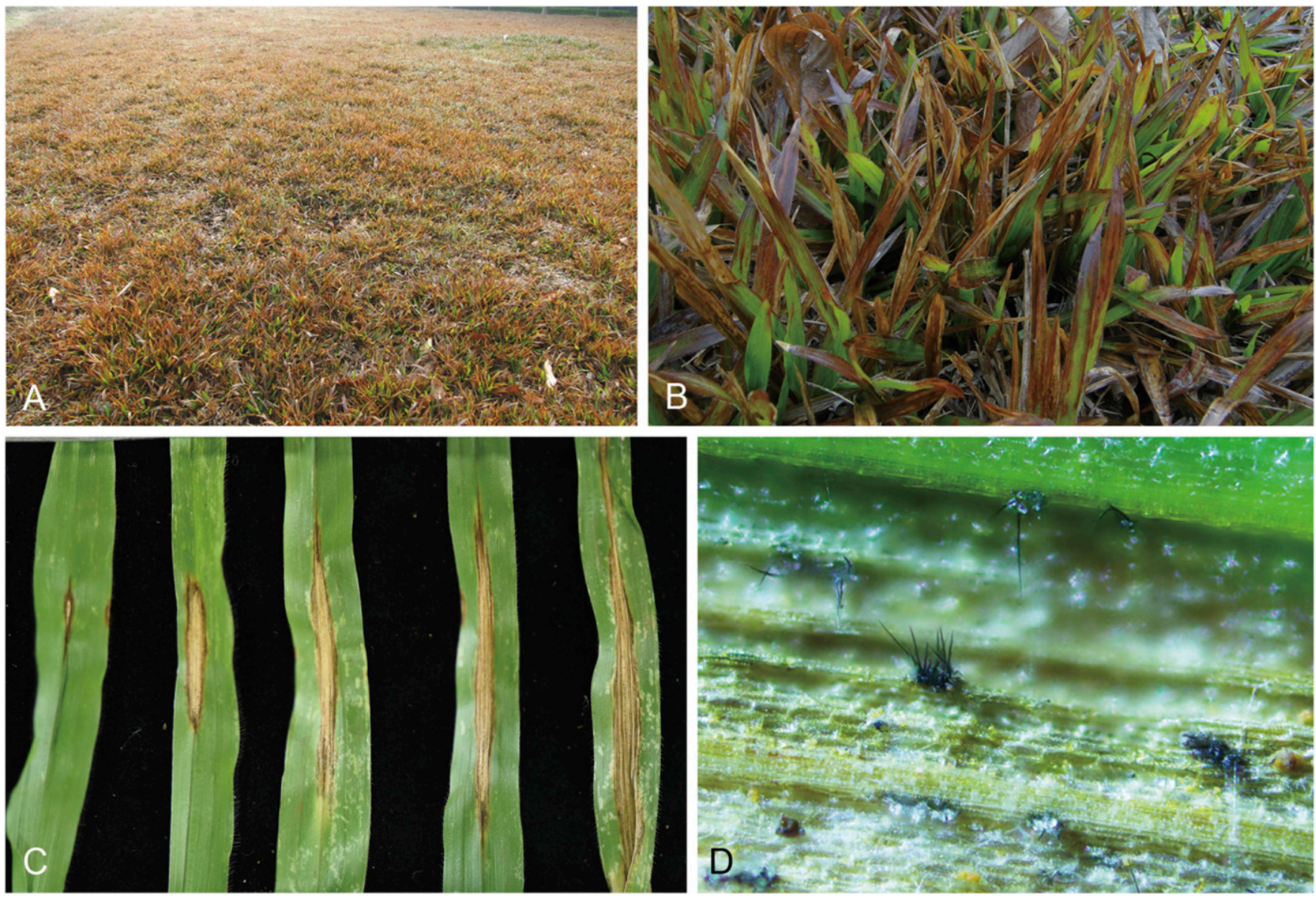

Fig. 1. Anthracnose disease on Axonopus compressus caused by Colletotrichum hainanense. A and B, Anthracnose symptoms on Axonopus compressus in the field. C, Lesions on infected leaves. D, Acervuli of $C$. hainanense on diseased leaf tissue. 
Additional material examined. China, Hainan Province, Haikou City, from leaf anthracnose of A. compressus, 8 April 2015, W. Zhang, culture YF10-2 = CBS 145901; Guangdong Province, Zhanjiang City, from leaf anthracnose of A. compressus, 20 December 2015, W. Zhang, culture ZW3-12 = CBS 145902 .

Notes: $C$. hainanense is phylogenetically closely related to $C$. paspali, $C$. nicholsonii, $C$. navitas, and $C$. graminicola, from which it can be distinguished morphologically based on their conidial dimensions. The conidia of $C$. hainanense are longer and wider (19.5 to $27.5 \times 4$ to $7 \mu \mathrm{m}$, mean $=23.6 \times 6.1 \mu \mathrm{m}, \mathrm{L} / \mathrm{W}$ ratio $=3.9)$ than those of $C$. paspali $(17.5$ to $24 \times 3$ to $5 \mu \mathrm{m}$, mean $=21.2 \times 4.1 \mu \mathrm{m}, \mathrm{L} / \mathrm{W}$ ratio $=5.1)$ and $C$. nicholsonii $(17.5$ to $23.5 \times 3.5$ to $5 \mu \mathrm{m}$, mean $=$ $19.9 \times 4.3 \mu \mathrm{m}, \mathrm{L} / \mathrm{W}$ ratio $=4.6)$ and shorter and wider than those of $C$. navitas $(34.2$ to $40.5 \times 2.8$ to $5 \mu \mathrm{m}$; mean $=37.9 \times 4.2 \mu \mathrm{m}$, $\mathrm{L} / \mathrm{W}$ ratio $=9.0)$ and $C$. graminicola $(21.4$ to $30.4 \times 3.9$ to $5.4 \mu \mathrm{m}$,
$\mathrm{L} / \mathrm{W}$ ratio $=5.5)($ Crouch et al. 2009a, c; Moriwaki and Tsukiboshi 2009).

C. axonopodis, reported as the causal agent of anthracnose disease of Axonopus fissifolius (syn. Axonopus affinis) in Australia, also forms curved conidia and irregularly shaped appressoria and belongs to the $C$. graminicola species complex (Crouch et al. 2009c). However, $C$. hainanense is morphologically and phylogenetically distinct from $C$. axonopodis. Conidia of $C$. hainanense are longer and wider than those of $C$. axonopodis ( 20 to $25 \times 3.5$ to $5 \mu \mathrm{m}$ ), and the appressoria of $C$. hainanense are larger than those of $C$. axonopodis ( 7.5 to $11.25 \times 5$ to $12.5 \mu \mathrm{m}$ ) (Crouch et al. 2009c). Moreover, colonies of C. hainanense on PDA are white to pale gray in the center and mouse gray toward the margin, in comparison with the pale tan-orange colonies of $C$. axonopodis. The ITS sequences of $C$. hainanense are only 95\% identical with those of C. axonopodis, generated in this study.

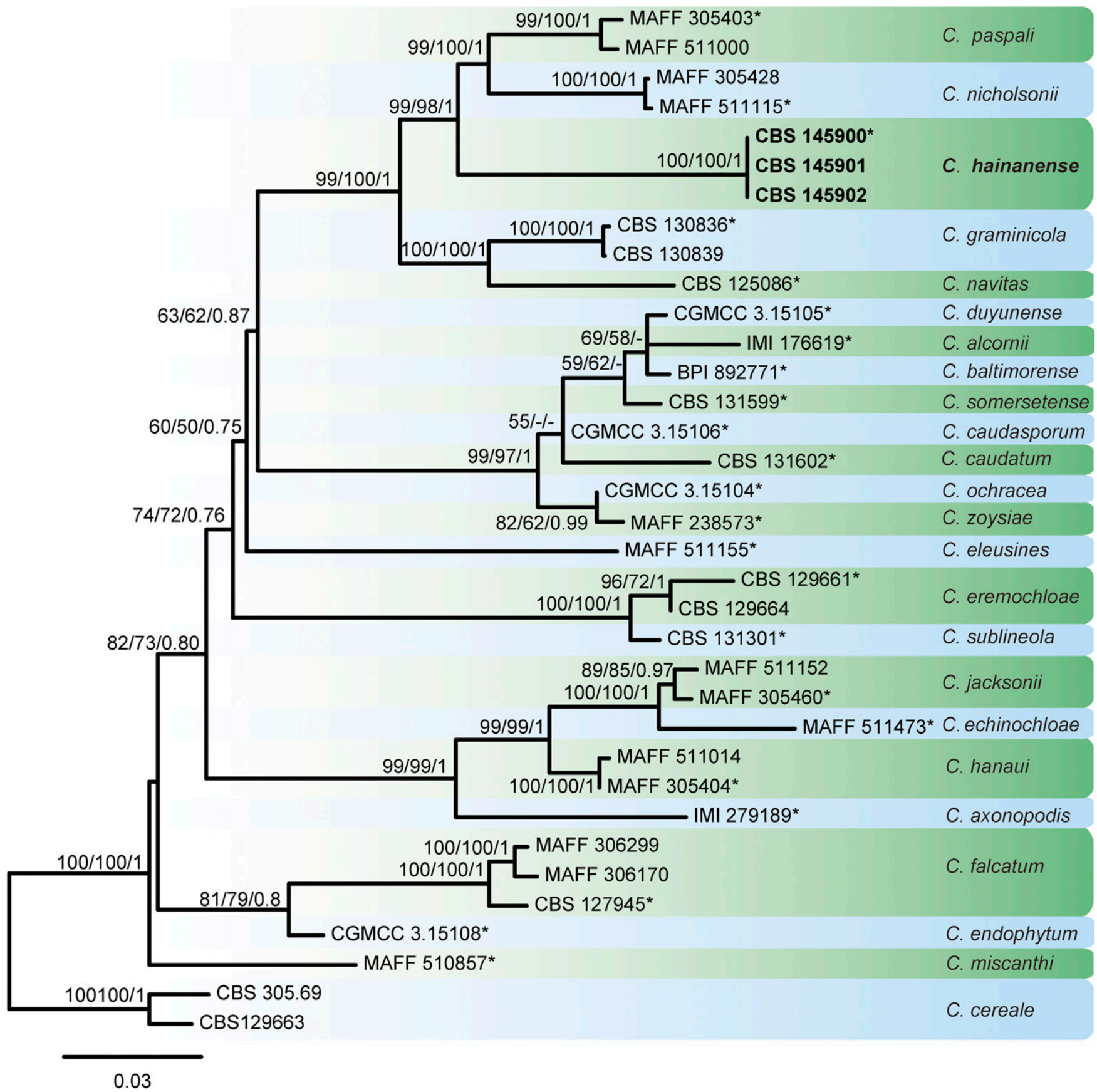

Fig. 2. Phylogenetic tree inferred from a maximum likelihood analysis based on a concatenated alignment of internal transcribed spacer, Sod2, Apn2, and Apn2/Mat1 sequences of 35 isolates of the Colletotrichum graminicola species complex. Bootstrap support values (BS) obtained with maximum likelihood (ML) and maximum parsimony (MP) $>50 \%$ and posterior probability (PP) values $>0.70$ are shown at the nodes (ML-BS/MP-BS/PP). The tree is rooted to Colletotrichum cereale strains CBS 305.69 and CBS 129663 . Numbers of ex-type strains are marked with an asterisk. Isolates of Colletotrichum hainanense are indicated in boldface. 
Because the available ITS sequence of $C$. axonopodis was not reliable to use as DNA barcode and the systematic position of the species was therefore unclear, it was not included in that last overview of the genus (U. Damm, personal communication). In the present study, an accurate ITS sequence of $C$. axonopodis was used for comparison and phylogenetic reconstruction. The multigene phylogenetic analysis also showed $C$. hainanense and $C$. axonopodis to belong to different main clades of the $C$. graminicola species complex.

C. hainanense can be identified with sequences of all loci available (ITS, Sod2, Apn2, Apn2/Mat1). In a BLASTn search on NCBI GenBank, the ITS sequence of the ex-type strain, CBS 145900, is $97 \%$ identical (18-nucleotide difference) with both the ex-type strain of C. navitas, CBS 125086, and that of C. paspali, MAFF 305403 (Crouch et al. 2009a, c). Closest matches in BLASTn searches with the Sod2, Apn2, and Apn2/Mat1 sequences of strain CBS 145900 showed $\leq 95 \%$ identity to sequences of the ex-type strains of
C. nicholsonii (MAFF 511115), C. paspali (MAFF 305403), C. navitas (CBS 125086), and Colletotrichum somersetense (CBS131599).

\section{Discussion}

In this study, we revealed the causal organism of a devastating anthracnose disease of $A$. compressus to be a new Colletotrichum species in the $C$. graminicola species complex by means of morphological and molecular methods and confirmed its pathogenicity to A. compressus.

Crouch et al. (2009c) used ITS, Sod2, Apn2, and Apn2/Mat1 gene regions to successfully identify several anthracnose pathogens that infect warm-season grasses. Our analysis, based on these four loci, revealed that the new species, $C$. hainanense, shares a common evolutionary history with other Colletotrichum species that infect warmseason grasses. These organisms are united broadly by a common host physiology ( $\mathrm{C} 4$ photosynthesis) and their morphology (the general falcate shape of their conidia). C. hainanense is most closely
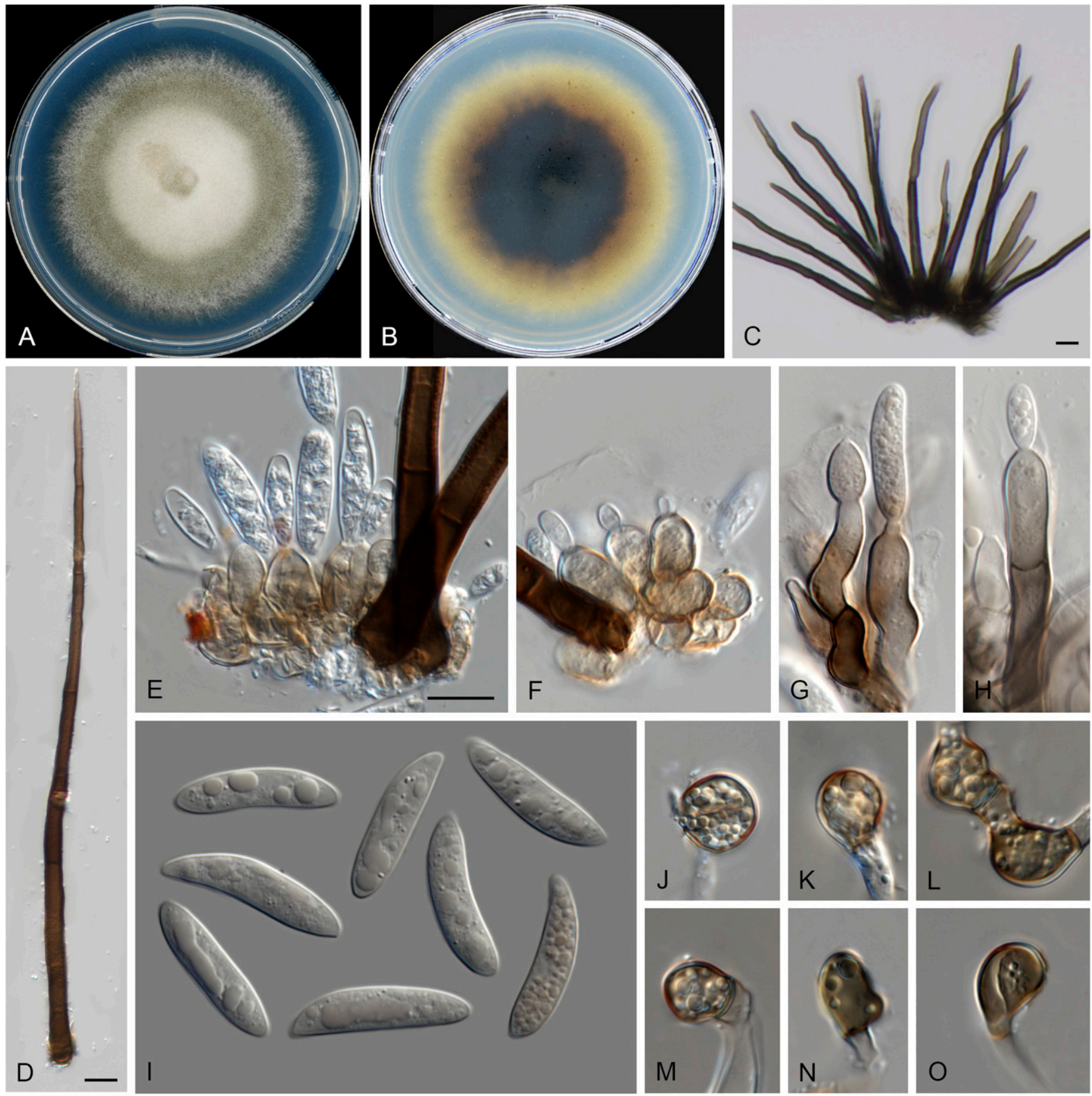

Fig. 3. Morphological characters of Colletotrichum hainanense. A and B, Colony on PDA after 14 days incubation (A, upper surface, B, reverse). C, Acervulus with setae. D, Seta. E to $\mathrm{H}$, Conidiogenous cells. I, Conidia. $\mathbf{J}$ to $\mathbf{O}$, Appressoria. Scale bars $=10 \mu \mathrm{m}$; scale bar on $\mathbf{E}$ applies to $\mathbf{E}$ to $\mathbf{O}$. 
related to $C$. paspali and $C$. nicholsonii. However, C. hainanense exhibits several unique traits that distinguish it from these species, specifically the molecular characters and size of its conidia.

The only strain of $C$. axonopodis that is available is the ex-type strain IMI 279189. Crouch et al. (2009c) also reported this species from A. fissifolius (syn. A. affinis) in the United States (Louisiana) and from A. compressus in United States (Georgia) and Honduras. These reports were apparently based on specimens, meaning on morphological data only. Reports of C. graminicola and C. sublineola on Axonopus spp. in Australia, Bolivia, Fiji, Guinea, Malaysia, Mauritius, and Trinidad and Tobago are from the premolecular era and before the studies by Crouch et al. (2009c, d) and mostly from lists of plant pathogens (Farr and Rossman 2019). All these reports must be confirmed by sequence data. However, they show that diseases of Axonopus spp. caused by Colletotrichum species are common in tropical countries. Because C. graminicola and C. sublineola are specific pathogens of Zea and Sorghum, respectively (Crouch and Beirn 2009; Crouch and Tomaso-Peterson 2012), the causal agents are more likely to be $C$. axonopodis, $C$. hainanense, or even additional species. Twenty-two Colletotrichum species have previously been regarded as accepted species in the $C$. graminicola species complex, of which 18 species were associated with grasses (Marin-Felix et al. 2017). The phylogenetic position of another species, previously described from Axonopus in Australia (Crouch et al. 2009c), C. axonopodis, was confirmed here as belonging to the $C$. graminicola species complex. The novel species $C$. hainanense, associated with carpetgrass in southern China, expands this complex to 24 species. Although based on a limited dataset, the pathogen was commonly found in high abundance; in some cases all carpetgrass plants in a lawn were affected. Further research on $C$. hainanense is needed in order to determine its regional and global distribution, its impact on the host plant, and biological characteristics.

\section{Acknowledgments}

We thank Dr. Shaun Pennycook (Landcare Research, Auckland, New Zealand) and Dr. Konstanze Bensch (Westerdijk Fungal Biodiversity Institute, Utrecht, The Netherlands) for correcting the name Colletotrichum axonopodis.

\section{Literature Cited}

Afanador-Kafuri, L., González, A., Gañán, L., Mejía, J. F., Cardona, N., and Alvarez, E. 2014. Characterization of the Colletotrichum species causing anthracnose in Andean blackberry in Colombia. Plant Dis. 98:1503-1513.

Cai, L., Hyde, K. D., Taylor, P. W. J., Weir, B., Waller, J., Abang, M. M., Zhang, J. Z., Yang, Y. L., Phoulivong, S., Liu, Z. Y., Prihastuti, H., Shivas, R. G., McKenzie, E. H. C., and Johnston, P. R. 2009. A polyphasic approach for studying Colletotrichum. Fungal Divers. 39:183-204.

Cannon, P. F., Damm, U., Johnston, P. R., and Weir, B. S. 2012. Colletotrichum: Current status and future directions. Stud. Mycol. 73:181-213.

Crouch, J. A. 2014. Colletotrichum caudatum s.l. is a species complex. IMA Fungus 5:17-30.

Crouch, J. A., and Beirn, L. A. 2009. Anthracnose of cereals and grasses. Fungal Divers. 39:19-44.

Crouch, J. A., Beirn, L. A., Cortese, L. M., Bonos, S. A., and Clarke, B. B. 2009a. Anthracnose disease of switchgrass caused by the novel fungal species Colletotrichum navitas. Mycol. Res. 113:1411-1421.

Crouch, J. A., Clarke, B. B., and Hillman, B. I. 2006. Unraveling evolutionary relationships among the divergent lineages of Colletotrichum causing anthracnose disease in turfgrass and maize. Phytopathology 96:46-60.

Crouch, J. A., Clarke, B. B., and Hillman, B. I. 2009b. What is the value of ITS sequence data in Colletotrichum systematics and species diagnosis? A case study using the falcate-spored graminicolous Colletotrichum group. Mycologia 101:648-656.

Crouch, J. A., Clarke, B. B., White, J. F., and Hillman, B. I. 2009c. Systematic analysis of the falcate-spored graminicolous Colletotrichum and a description of six new species from warm season grasses. Mycologia 101:717-732.

Crouch, J. A., and Tomaso-Peterson, M. 2012. Anthracnose disease of centipedegrass turf caused by Colletotrichum eremochloae, a new fungal species closely related to Colletotrichum sublineola. Mycologia 104:1085-1096.

Crouch, J. A., Tredway, L. P., Clarke, B. B., and Hillman, B. I. 2009d. Phylogenetic and population genetic divergence correspond with habitat for the pathogen Colletotrichum cereale and allied taxa across diverse grass communities. Mol. Ecol. 18:123-135.

Crous, P. W., Verkley, G. J. M., Groenewald, J. Z., and Samson, R. A., eds. 2019. Fungal Biodiversity. Westerdijk Laboratory Manual Series 1: 1-425. Westerdijk Fungal Biodiversity Institute, Utrecht, The Netherlands.
Damm, U., Cannon, P. F., Woudenberg, J. H. C., and Crous, P. W. 2012b. The Colletotrichum acutatum species complex. Stud. Mycol. 73:37-113.

Damm, U., Cannon, P. F., Woudenberg, J. H. C., Johnston, P. R., Wei, B. S., Tan, Y. P., Shivas, R. G., and Crous, P. W. 2012a. The Colletotrichum boninense species complex. Stud. Mycol. 73:1-36.

Damm, U., O'Connell, R. J., Groenewald, J. Z., and Crous, P. W. 2014. The Colletotrichum destructivum species complex: Hemibiotrophic pathogens of forage and field crops. Stud. Mycol. 79:49-84.

Damm, U., Sato, T., Alizadeh, A., Groenewald, J. Z., and Crous, P. W. 2019. The Colletotrichum draecaenophilum, C. magnum and C. orchidearum species complexes. Stud. Mycol. 92:1-46.

Damm, U., Woudenberg, J. H. C., Cannon, P. F., and Crous, P. W. 2009 Colletotrichum species with curved conidia from herbaceous hosts. Fungal Divers. 39:45-87.

Farr, D. F., and Rossman, A. Y. 2019. Fungal Databases, U.S. National Fungus Collections, ARS, USDA. Retrieved 9 October 2019 from https://nt.ars-grin.gov/ fungaldatabases/.

Guarnaccia, V., Groenewald, J. Z., Polizzi, G., and Crous, P. W. 2017. High species diversity in Colletotrichum associated with citrus diseases in Europe. Persoonia 39:32-50.

Hillis, D. M., and Bull, J. J. 1993. An empirical test of bootstrapping as a method for assessing confidence in phylogenetic analysis. Syst. Biol. 42:182-192.

Johnston, P. R., and Jones, D. 1997. Relationships among Colletotrichum isolates from fruit-rots assessed using rDNA sequences. Mycologia 89: 420-430.

Katoh, K., and Standley, D. M. 2013. MAFFT multiple sequence alignment software version 7: Improvements in performance and usability. Mol. Biol. Evol. 30:772-780.

Kumar, S., Stecher, G., and Tamura, K. 2016. MEGA7: Molecular Evolutionary Genetics Analysis version 7.0 for bigger datasets. Mol. Biol. Evol. 33: 1870-1874.

Marin-Felix, Y., Groenewald, J. Z., Cai, L., Chen, Q., Marincowitz, S., Barnes, I., Bensch, K., Braun, U., Camporesi, E., Damm, U., de Beer, Z. W., Dissanayake, A., Edwards, J., Giraldo, A., Hernández-Restrepo, M., Hyde, K. D., Jayawardena, R. S., Lombard, L., Luangsa-ard, J., McTaggart, A. R., Rossman, A. Y., Sandoval-Denis, M., Shen, M., Shivas, R. G., Tan, Y. P., van der Linde, E. J., Wingfield, M. J., Wood, A. R., Zhang, J. Q., Zhang, Y., and Crous, P. W. 2017. Genera of phytopathogenic fungi: GOPHY 1. Stud. Mycol. 86:99-216.

Moriwaki, J., and Tsukiboshi, T. 2009. Colletotrichum echinochloae, a new species on Japanese barnyard millet (Echinochloa utilis). Mycoscience 50: 273-280.

Nylander, J. A. A. 2004. MrModeltest version 2. Program distributed by the author. Evolutionary Biology Centre, Uppsala University.

Prihastuti, H., Cai, L., and Hyde, K. D. 2010. Neotypification of Colletotrichum falcatum, the causative agent of red-rot disease in sugarcane. Sydowia 62: 283-293.

Ronquist, F., Teslenko, M., Van der Mark, P., Ayres, D. L., Darling, A., Hohna, S., Larget, B., Liu, L., Suchard, M. A., and Huelsenbeck, J. P. 2012. MrBayes 3.2: Efficient Bayesian phylogenetic inference and model choice across a large model space. Syst. Biol. 61:539-542.

Sutton, B. C. 1992. The genus Glomerella and its anamorph Colletotrichum. Pages 1-26 in: Colletotrichum: Biology, Pathology and Control. J. A. Bailey and M. J. Jeger, eds. CAB international, Wallingford.

Swofford, D. L. 2002. PAUP*: Phylogenetic Analysis Using Parsimony. (*and Other Methods), version 4.0b10. Sinauer Associates, Sunderland, MA.

Tao, G., Liu, Z. Y., Liu, F., Gao, Y. H., and Cai, L. 2013. Endophytic Colletotrichum species from Bletilla ochracea (Orchidaceae), with description of seven new species. Fungal Divers. 61:139-164.

von Arx, J. A. 1957. Die Arten der Gattung Colletotrichum Cda. Phytopathol. Z. 29:414-468.

Weir, B., Damm, U., and Johnston, P. R. 2012. The Colletotrichum gloeosporioides species complex. Stud. Mycol. 73:115-180.

White, T. J., Bruns, T., Lee, S., and Taylor, J. 1990. Amplification and direct sequencing of fungal ribosomal RNA genes for phylogenetics. Pages 315-322 in: PCR Protocols: A Guide to Method and Applications. Academic Press, New York, NY.

Xi, J. B., Chen, P., Zheng, Y. Z., and Yang, Z. Y. 2006. An investigation of Axonopus compressus germplasm resources in China. Acta Pratac. Sin. 15 93-99.

Xu, H., Zhou, R., Fu, J. F., Yuan, Y., Ge, X. X., and Damm, U. 2018. Colletotrichum atractylodicola sp. nov.: The anthracnose pathogen of Atractylodes chinensis in China. Mycol. Prog. 17:393-402.

Zhang, W., Liu, G. D., and Nan, Z. B. 2015a. Identification and biological characteristics of Sclerotinia homoeocarpa causing dollar spot on 4 warmseason turfgrass. Acta Pratac. Sin. 24:124-131.

Zhang, W., Liu, J. X., Huo, P. H., and Nan, Z. B. 2017. Curvularia lunata causes a leaf spot on Carpetgrass (Axonopus compressus) in China. Plant Dis. 101:507.

Zhang, W., Nan, Z. B., Tian, P., Hu, M. J., Gao, Z. Y., and Li, M. 2015b. Microdochium paspali, a new species causing seashore paspalum disease in south China. Mycologia 107:80-89. 